\title{
VARIASI MORFOMETRIK IKAN MUJAIR (Oreochromis mossambicus) PADA EKOSISTEM RAWA (LENTIK WATER) DI WILAYAH PRAFI, MASNI DAN SIDEY, KABUPATEN MANOKWARI
}

Sigit Prafiadi*1, Enik Maturahmah²

1,2 STKIP Muhammadiyah Manokwari, Jl. Trikora Rendani, Anday, Arfai, Papua Barat, 98312, Indonesia

*Corresponding author, e-mail: sigitprafiadi@gmail.com

\begin{abstract}
ABST RAC T
This study aims to determine the pattern of breeding, adaptability to the environment and feeding processes in tilapia fish Oreochromis mossambicus through morphological data, morphological data obtained through morphometric measurements that can be used to formulate the extent of the threat to local species because tilapia is an invasive fish species with morphological data. Fairly high reproduction in freshwater waters. The location of this research is swamp waters in Manokwari Regency, namely Prafi, Masni and Sidey Regions. Morphometric measurements using 14 standards. Morphometric measurement results of male fish showed that the width of the tail fin (CFW) there was a significant difference in the width of the tail fin (CFL) between the tilapia fish in the Prafi swamp with the other two marshes, the width of the tilapia fish tail fins in the Masni and Sidey swamps did not differ significantly. In female fish measurements (DFL) showed that there were significant differences while the CFW measurements contained in the Prafi swamp were different from the other two marshes. The results of the morphometric measurements show how the morphological characteristics of tilapia fish will have an impact on local fish and the amount of natural food in the Swamp.
\end{abstract}

Keywords: Invasive species, Morfometric, Oreochromis mossambicus, Swamp

\section{PENDAHULUAN}

Ekosistem perairan tawar secara umum dibagi menjadi 2 yaitu perairan mengalir (lotic water) dan perairan menggenang (lentic water) (Utomo \& Chalif, 2014). Perairan lentik adalah kumpulan masa air yang relatif diam atau tenang seperti danau, situ, rawa, waduk atau telaga (Dewiyanti et al. 2015: Marwoto \& Isnaningsih, 2014). Rawa merupakan ekosistem perairan menggenang yang reltif dangkal, dinding landai dan daerah litoral sangat produktif (Satino, 2010). Rawa terbentuk karena proses pendangkalan dari danau, waduk, atau karena proses yang lain seperti karena gempa yang mengakibatkan suatu daerah turun tetapi tidak dalam, atau karena aktivitas angin, dan pasang surut air laut (rawa asin/payau) (Satino, 2010).

Ekosistem rawa di daerah dataran Papua Barat secara alami terdapat di perairan limnetik yang dangkal dan berair sepanjang tahun, tergenang di dataran rendah pada ketinggian $100 \mathrm{~m}$, yang menggenangi cekungan yang berbatasan langsung dengan garis pantai (Kartikasari et al. 2012). Kualitas air pada sistem ini bervariasi, salinitasnya 0,5\%o (konduktivitas 100-300 mhos), dengan pH 6,0-7,5 (Kartikasari et al. 2012). 
Ciri-ciri fauna ekosistem alami dan buatan mencakup beberapa jenis ikan terutama ikan mata biru, ikan pelangi, ikan kaca dan belontok serta ditemukan pula ikan mujahir (Nuraini, 2012). Ikan mujair (Oreochormis mossambicus) telah ditetapkan sebagai salah satu invasive alien spesies yang dapat memberikan dampak negatif terbesar bagi habitat ikan lokal (Syafei \& Sudinno, 2018). Invasive alien spesies merupakan spesies yang didatangkan dari luar habitat asli dan dapat berdampak negatif terhadap habitat asli tersebut (Gunawan \& Jumadi, 2016). Salah satu dampak negatif tersebut yaitu berupa ancaman terhadap spesies lokal pada suatu habitat asli yang mengalami introduksi (Namboothri et al. 2012). Introduksi ikan mujair selalu sukses pada berbagai native spesies dikarenakan siklus generasinya yang pendek, rentang pertumbuhan yang cepat, memiliki kemampuan toleransi terhadap berbagai kondisi lingkungan, memiliki tingkah laku yang agresif, dan bersifat omnivore (Crosetti, 2012). Adanya introduksi Oreochormis mossambicus pada waduk Prafi, Masni, dan Sidey dapat mengancam habitat dari spesies ikan endemik yang berada pada waduk tersebut. Sampai saat ini belum ada data morfometrik ikan mujair di ekosistem rawa (lentik water) di wilayah Prafi, Masni dan Sidey Kabupaten Manokwari, oleh sebab itu sangatlah baik jika dilakukan peneltian tentang morfomertik ikan mujair di wilayah tersebut untuk melihat bagaiamana populasi ikan mujair di kosistem rawa (lentik water) di wilayah Prafi, Masni dan Sidey Kabupaten Manokwari.

\section{METODE}

\section{Studi Area}

Penelitian ini dilakukan Perairan Rawa diWilayah Prafi, Masni dan Sidey, serta di Laboratorium IPA Dasar, Jurusan Biologi STKIP Muhammadiyah Manokwari.

\section{Alat dan Bahan}

Alat yang akan digunakan pada penelitian ini antara lain mistar, jaring ikan, timbangan, alat tulis, cawan petri, jangka sorong, ember, thermometer, pH meter, konduktivity meter, dan sacchi disk. Sedangkan bahan penelitian yang digunakan yaitu Mujair (Oreochromis mossambicus).

\section{Teknik Pengambilan Sampel}

Teknik pengambilan sampel ikan mengikuti standar prosedur Gusriyeni et al. (2017), yakni mengunakan jaring apung, pancing dan strum (Backpack electronic fishing) 12 volt di setiap rawa yang ada di ketiga wilayah tersebut. Ikan Mujair (Oreochromis mossambicus) diambil sebanyak 10 ekor tiap lokasi dengan ukuran 10-9 cm (Naeem et al. 2011). Pengambilan sampel di mulai pada pagi hari hingga malam hari yakni pada pukul 09.00 WIT sampai 21.00 WIT. Ikan yang tertangkap kemudian dibius dengan chloroform untuk di bedakan jenis kelaminnya yaitu pada betina terdapat tiga buah lubang pada urogenital, yaitu dubur, lubang pengeluaran telur dan lubang urin. Pada ujung sirip berwarna pucat kemerah-merahan, warna perut putih, warna dagu putih, dan jika di tekan tidak mengeluarkan cairan sperma. Selanjutnya kemudian dibawa kelaboratorium untuk pengukuran morfometriknya. 


\section{Pengukuran Morfometrik}

Beberapa pengukuran standar yang digunakan pada ikan menurut Naeem, et al. (2011) antara lain panjang total (TL), panjang standar (SL), panjang kepala (HL), ketebalan ikan (BG), panjang sirip punggung (DFL), panjang dasar sirip punggung (DFB), panjang sirip dada (PtFL), panjang dasar sirip dada (PtFB), panjang sirip perut (PvFL), panjang dasar sirip perut (PvFB), panjang sirip dubur (AFL), panjang dasar sirip dubur (AFB), panjang sirip ekor (CFL), dan lebar sirip ekor (CFW). Pengukuran morfometrik dilakukan pada ikan dengan jenis kelamin jantan maupun betina dengan jumlah minimal 10 ekor dengan ukuran yang sama, berkisar antara 10-19 cm.

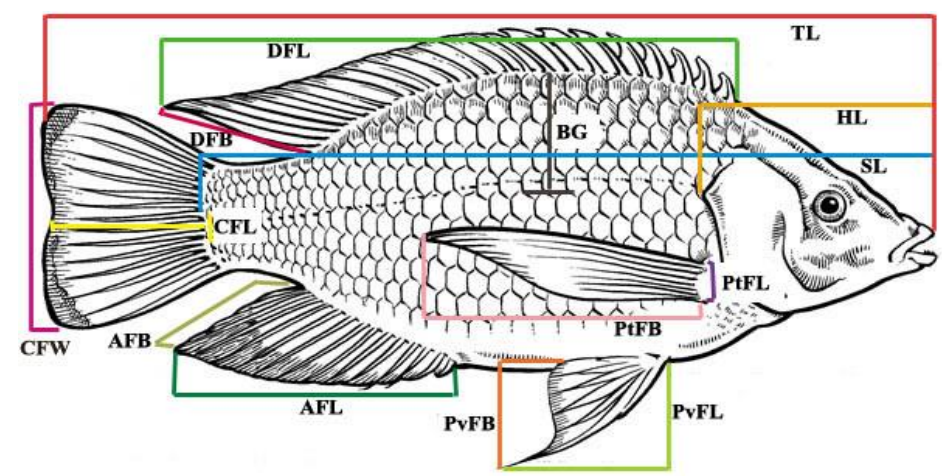

Gambar 1. Diagram pengukuran morfometrik (Naeem et al. 2011).

\section{Analisa Data}

Hasil pengukuran karakter sampel diuji dengan mengunakan uji anova twoway namun jika data tidak berdistribusi normal dan homogen maka akan di uji mengunakan uji Kruskal-Wallis menggunakan program IBM SPSS Statistics 20. Analisa Kruskal Walis digunakan untuk menguraikan keragaman total data menjadi komponen-komponen yang mengukur berbagai sumber keragaman. Selanjutnya untuk mengetahui tingkat variasi spesies ikan diolah dengan mengunakan software PAST pada analisis PCA (Principal Component Analisis).

\section{HASIL DAN PEMBAHASAN}

Pengukuran meristik ikan mujair dilakukan pada empat karakter morfologisnya, yaitu jari-jari sirip, tipe sisik, tipe ekor, dan bentuk ekor. Jari-jari sirip ikan mujair yang diamati memiliki rumus D XV-XVII, 12-13. Hal ini mengindikasikan bahwa ikan mujair yang diamati secara umum memiliki jari-jari keras dengan kisaran jumlah 15 -17, dan memiliki jari-jari lunak dengan kisaran jumlah 12-13. Adapun tipe sisik yang dimiliki ikan mujair adalah tipe ctenoid.

Tabel 1. Meristik Ikan Mujair (Oreochormis mosambicus)

\begin{tabular}{cc}
\hline Karakter Meristik & Hasil Pengamatan \\
\hline Jari-Jari Sirip & D XV-XVII, 12-13 \\
Tipe Sisik & Ctenoid \\
Tipe Ekor & Truncate \\
Bentuk Ekor & Homocercal \\
\hline
\end{tabular}


Berdasarkan hasil pengamatan tipe ekor dan bentuk ekor, ikan mujair memiliki tipe ekor truncate dengan bentuk ekor homocercal. Selanjutnya Pengamatan morfometrik dilakukan sebanyak 14 parameter. Berdasarkan hasil pengukuran morfometrik ikan mujair jantan mengindikasikan bahwa terdapat perbedaan yang signifikan pada panjang total (TL) ikan mujair di Rawa Prafi dengan kedua rawa yang lain, sedangkan panjang total ikan Mujair pada Rawa Masni yaitu $(17,8)$ dan Rawa Sidey $(18,32)$ tidak berbeda secara signifikan. Selanjutnya, terdapat perbedaan yang signifikan pada panjang standard $(S L)$ ikan mujair di Rawa Prafi $(12,56 \mathrm{~cm})$ dengan kedua rawa yang lain, sedangkan panjang standar ikan mujair pada Rawa Masni $(14,06)$ dan Rawa Sidey $(14,22)$ tidak berbeda secara signifikan. Untuk panjang kepala $(H L)$, terdapat perbedaan panjang kepala yang signifikan antara ikan mujair di Rawa Prafi $(4,21)$ dengan Rawa Sidey $(4,82)$. Hasil pengukuran ketebalan badan $(B G)$ ikan mujair menunjukkan bahwa terdapat perbedaan ketebalan badan yang signifikan antara ikan mujair di Rawa Prafi $(2,44)$ dengan kedua rawa yang lain, sedangkan ketebalan badan ikan mujair pada Rawa Masni $(2,64)$ dan Rawa Sidey $(2,92)$ tidak berbeda secara signifikan.

Hasil pengukuran panjang sirip dorsal (DFL) ikan mujair menunjukkan bahwa tidak terdapat perbedaan panjang sirip dorsal yang signifikan pada ikan mujair di ketiga rawa yang diamati. Hasil pengukuran panjang pangkal sirip dorsal $(D F B)$ ikan mujair menunjukkan bahwa terdapat perbedaan panjang dasar sirip dorsal yang signifikan antara ikan mujair di Rawa Prafi $(7,5)$ dengan Rawa Sidey $(8,52)$. Hasil pengukuran panjang sirip dada $(P t F L)$ ikan mujair menunjukkan bahwa terdapat perbedaan yang signifikan antara ikan mujair di Rawa Prafi $(4,86)$ dengan kedua rawa yang lain, sedangkan panjang sirip dada ikan mujair pada Rawa Masni $(5,65)$ dan Rawa Sidey $(5,73)$ tidak berbeda secara signifikan. Untuk panjang pangkal sirip dada (PtFB), terdapat perbedaan panjang dasar sirip dada yang signifikan antara ikan mujair di Rawa Prafi $(0,96)$ dengan Rawa Sidey $(1,12)$, sedangkan pada ikan mujair pada Rawa Prafi dan Rawa Masni $(0,96)$ tidak berbeda secara signifikan.

Hasil pengukuran panjang sirip perut $(P v F L)$ ikan mujair menunjukkan bahwa tidak terdapat perbedaan signifikan pada ikan mujair di ketiga rawa yang diamati. Hasil pengukuran panjang dasar sirip perut $(P v F B)$ ikan mujair menunjukkan bahwa terdapat perbedaan yang signifikan antara ikan mujair di Rawa Masni $(0,6)$ dengan Rawa Sidey $(0,86)$. Hasil pengukuran panjang sirip anal $(A F L)$ ikan mujair menunjukkan bahwa tidak terdapat perbedaan yang signifikan pada ikan mujair di ketiga rawa yang diamati. Hasil pengukuran panjang pangkal sirip anal $(A F B)$ ikan mujair menunjukkan bahwa terdapat perbedaan panjang pangkal sirip anal yang signifikan antara ikan mujair di Rawa Prafi $(2,28)$ dengan kedua rawa yang lain, yakni pada Rawa Masni $(2,65)$ dan Rawa Sidey $(2,71)$ tidak berbeda secara signifikan. Hasil pengukuran panjang sirip ekor ikan mujair (CFL) menunjukkan bahwa terdapat perbedaan panjang sirip ekor yang signifikan antara ikan mujair di Rawa Prafi $(3,11)$ dengan kedua rawa yang lain, yaitu pada Rawa Masni $(3,49)$ dan Rawa Sidey $(3,77)$ 
tidak berbeda secara signifikan. Hasil pengukuran lebar sirip ekor ( $C F W$ ) ikan mujair menunjukkan bahwa terdapat perbedaan yang signifikan antara ikan mujair di Rawa Prafi $(4,16)$ dengan kedua rawa yang lain, sedangkan lebar sirip ekor ikan mujair pada Rawa Masni $(5,14)$ dan Rawa Sidey $(5,04)$ tidak berbeda secara signifikan.

Tabel 2. Data Hasil Pengukuran Morfometrik Ikan Mujair Jantan

\begin{tabular}{cccc}
\hline \multirow{2}{*}{ Parameter Morfometrik } & \multicolumn{3}{c}{ Mean \pm SD } \\
\cline { 2 - 4 } & Rawa Prafi & Rawa Masni & Rawa Sidey \\
\hline Total Length (TL) & $15,82 \pm 1,25^{\mathrm{a}}$ & $17,8 \pm 0,7^{\mathrm{b}}$ & $18,32 \pm 0,67^{\mathrm{b}}$ \\
Standard Length (SL) & $12,56 \pm 0,95^{\mathrm{a}}$ & $14,06 \pm 0,68^{\mathrm{b}}$ & $14,22 \pm 0,58^{\mathrm{b}}$ \\
Head Length (HL) & $4,21 \pm 0,37^{\mathrm{a}}$ & $4,52 \pm 0,33^{\mathrm{b}}$ & $4,82 \pm 0,36^{\mathrm{b}}$ \\
Body Girth (BG) & $2,28 \pm 0,17^{\mathrm{a}}$ & $2,58 \pm 0,23^{\mathrm{b}}$ & $2,51 \pm 0,19^{\mathrm{b}}$ \\
Dorsal Fin Length (DFL) & $2,44 \pm 0,35^{\mathrm{a}}$ & $2,64 \pm 0,37^{\mathrm{b}}$ & $2,92 \pm 0,66^{\mathrm{a}}$ \\
Dorsal Fin Base (DFB) & $7,5 \pm 0,47^{\mathrm{a}}$ & $8,18 \pm 1,13^{\mathrm{a}}$ & $8,52 \pm 0,45^{\mathrm{b}}$ \\
Pectoral Fin Length (PtFL) & $4,86 \pm 0,41^{\mathrm{a}}$ & $5,65 \pm 0,43^{\mathrm{b}}$ & $5,73 \pm 0,41^{\mathrm{a}}$ \\
Pectoral Fin Base (PtFB) & $0,96 \pm 0,05^{\mathrm{a}}$ & $0,96 \pm 0,11^{\mathrm{a}}$ & $1,12 \pm 0,09^{\mathrm{b}}$ \\
Pelvic Fin Length (PvFL) & $3,84 \pm 0,38^{\mathrm{a}}$ & $4,04 \pm 0,21^{\mathrm{a}}$ & $3,94 \pm 0,23^{\mathrm{a}}$ \\
Pelvic Fin Length (PvFB) & $0,73 \pm 0,17^{\mathrm{ab}}$ & $0,6 \pm 0,08^{\mathrm{a}}$ & $0,86 \pm 0,14^{\mathrm{a}}$ \\
Anal Fin Length (AFL) & $2,91 \pm 0,73^{\mathrm{a}}$ & $2,48 \pm 0,28^{\mathrm{a}}$ & $3,00 \pm 0,39^{\mathrm{a}}$ \\
Anal Fin Base (AFB) & $2,28 \pm 0,13^{\mathrm{a}}$ & $2,65 \pm 0,21^{\mathrm{b}}$ & $2,71 \pm 0,23^{\mathrm{b}}$ \\
Caudal Fin Length (CFL) & $3,11 \pm 0,28^{\mathrm{a}}$ & $3,49 \pm 0,29^{\mathrm{b}}$ & $3,77 \pm 0,29^{\mathrm{b}}$ \\
Caudal Fin Width (CFW) & $4,16 \pm 0,79^{\mathrm{a}}$ & $5,14 \pm 0,58^{\mathrm{b}}$ & $5,04 \pm 0,94^{\mathrm{b}}$ \\
\hline
\end{tabular}

Berdasarkan hasil pengukuran morfometrik Oreocromis mossambicus betina pada tiga rawa yaitu Rawa Prafi, Masni dan Sidey menunjukkan adanya variasi ukuran dari ikan mujair di tiga waduk tersebut. Pada karakter TL, SL, BG, DFB, PtFL, PtFB, PvFB, AFL, CFL, menunjukkan terdapat perbedaan variasi morfometrik pada masing-masing di ketiga rawa tersebut. Untuk karakter DFL tidak memiliki perbedaan variasi morfometrik. Sedangkan karakter PvFL yang terdapat pada Rawa Sidey yaitu sebesar 3,91 berbeda nyata dengan dua rawa yang lain yaitu Rawa Masni dan Rawa Prafi, begitu pula dengan karakter CFW yang terdapat pada Rawa Prafi sebesar 3,79 berbeda nyata dengan kedua rawa yang terdapat pada Rawa Masni dan Rawa Sidey.

Tabel 3. Data hasil pengukuran morfometrik ikan mujair betina

\begin{tabular}{cccc}
\hline \multirow{2}{*}{ Parameter Morfometrik } & \multicolumn{3}{c}{ Mean \pm SD } \\
\cline { 2 - 4 } & Rawa Prafi & Rawa Masni & Rawa Sidey \\
\hline Total Length (TL) & $13,08 \pm 0,67^{\mathrm{a}}$ & $15,0 \pm 1,1^{\mathrm{b}}$ & $17,98 \pm 0,69^{\mathrm{c}}$ \\
Standard Length (SL) & $10,35 \pm 0,56^{\mathrm{a}}$ & $11,89 \pm 0,97^{\mathrm{b}}$ & $13,95 \pm 0,61^{\mathrm{c}}$ \\
Head Length (HL) & $3,18 \pm 0,12^{\mathrm{a}}$ & $3,81 \pm 0,26^{\mathrm{b}}$ & $4,61 \pm 0,35^{\mathrm{c}}$ \\
Body Girth (BG) & $1,76 \pm 0,17^{\mathrm{a}}$ & $2,21 \pm 0,25^{\mathrm{b}}$ & $2,52 \pm 0,20^{\mathrm{c}}$ \\
Dorsal Fin Length (DFL) & $1,25 \pm 0,13^{\mathrm{a}}$ & $3,00 \pm 3,03^{\mathrm{b}}$ & $2,52 \pm 0,13^{\mathrm{a}}$ \\
Dorsal Fin Base (DFB) & $5,98 \pm 0,43^{\mathrm{a}}$ & $7,2 \pm 0,71^{\mathrm{b}}$ & $8,33 \pm 0,47^{\mathrm{c}}$ \\
Pectoral Fin Length (PtFL) & $3,93 \pm 0,27^{\mathrm{a}}$ & $4,71 \pm 0,42^{\mathrm{b}}$ & $5,49 \pm 0,37^{\mathrm{c}}$ \\
Pectoral Fin Base (PtFB) & $0,5 \pm 0,07^{\mathrm{a}}$ & $0,73 \pm 0,11^{\mathrm{b}}$ & $0,92 \pm 0,09^{\mathrm{c}}$ \\
Pelvic Fin Length (PvFL) & $3,01 \pm 0,29^{\mathrm{a}}$ & $3,53 \pm 0,37^{\mathrm{b}}$ & $3,91 \pm 0,31^{\mathrm{b}}$ \\
Pelvic Fin Length (PvFB) & $0,49 \pm 0,06^{\mathrm{a}}$ & $0,56 \pm 0,07^{\mathrm{b}}$ & $0,74 \pm 0,06^{\mathrm{c}}$ \\
Anal Fin Length (AFL) & $1,47 \pm 0,16^{\mathrm{a}}$ & $1,99 \pm 0,22^{\mathrm{b}}$ & $2,53 \pm 0,19^{\mathrm{c}}$ \\
Anal Fin Base (AFB) & $1,71 \pm 0,18^{\mathrm{a}}$ & $2,3 \pm 0,12^{\mathrm{b}}$ & $2,59 \pm 0,23^{\mathrm{c}}$ \\
Caudal Fin Length (CFL) & $2,75 \pm 0,14^{\mathrm{a}}$ & $3,45 \pm 0,28^{\mathrm{b}}$ & $3,85 \pm 0,37^{\mathrm{c}}$ \\
Caudal Fin Width (CFW) & $3,79 \pm 0,42^{\mathrm{a}}$ & $4,38 \pm 0,6^{\mathrm{b}}$ & $3,32 \pm 0,24^{\mathrm{c}}$ \\
\hline
\end{tabular}


Berdasarkan uji Kruskal walis untuk mengetahui sejauh mana perbedaan karakter morfometrik ikan mujair jantan di ketiga rawa tersebut didapatkan hasil $\mathrm{p}$ $=0,798>\alpha(0,05)$, dari data di atas dapat disimpulkan bahwa data pengukuran morfometrik yang terdapat di ketiga rawa tersebut tidak berbeda secara signifikan. Untuk hasil Pengukuran morfometrik ikan mujair betina yang didapat dari ketiga tempat tersebut memperlihatkan uji kruskal wallis sebesar $p=0,469>\alpha$ dari hasil perhitungan inipun dapat disimpulkan bahwa data pengukuran morfometrik pada mujair betina tidak berbeda nyata secara signifikan. Walaupun dari hasil analisa kruskal wallis tidak berbeda nyata, perbedaan masih dapat dilihat dari hasil Analisa PCA.

Metode PCA digunakan sebagai alat untuk menvisualisasi data dari dimensidimensi yang berbeda dalam atribut yang bersifat pengenalan (Dzakaria et al. 2010) Hasil dari pengukuran melalui PCA juga menunjukkan bagaimana karakter morfologi ikan mujair baik jantan maupun betina yang terdapat di Rawa Prafi memiliki ukuran yang berbeda yakni lebih kecil bila dibandingkan dengan ukuran ikan mujair yang ada di Rawa Masni maupun Rawa Sidey. Dari hasil visualisasi ini dapat dipastikan bahwa pertumbuhan ikan mujair yang ada di Rawa Masni dan Rawa Sidey lebih cepat bila dibandingkan dengan ikan mujair yang ada di Rawa Prafi. Keadaan ini tentunya akan berdampak pada jumlah pakan alami yang ada di Rawa tersebut dan pada keberadaan ikan lokal yang akan besaing dengan ikan mujair dalam memperoleh makanan.

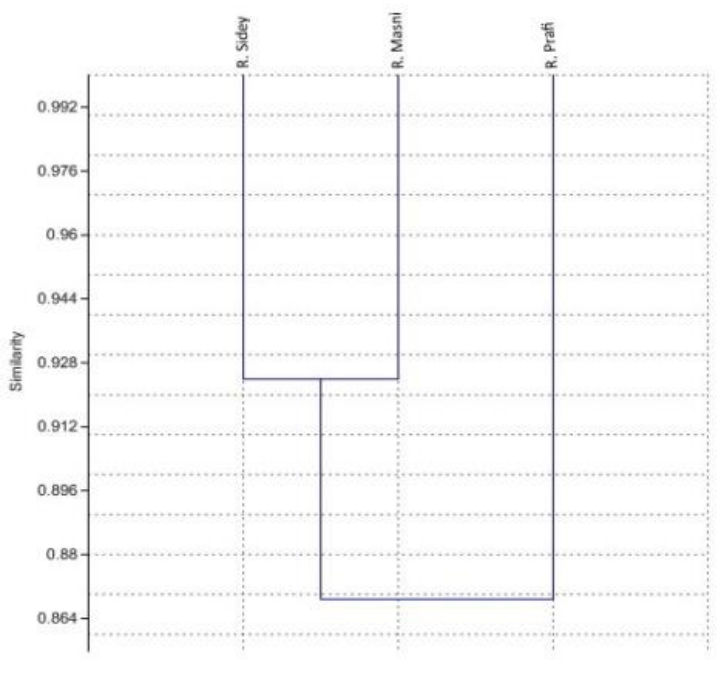

Gambar 1. Cluster PCA Ikan Mujair Betina

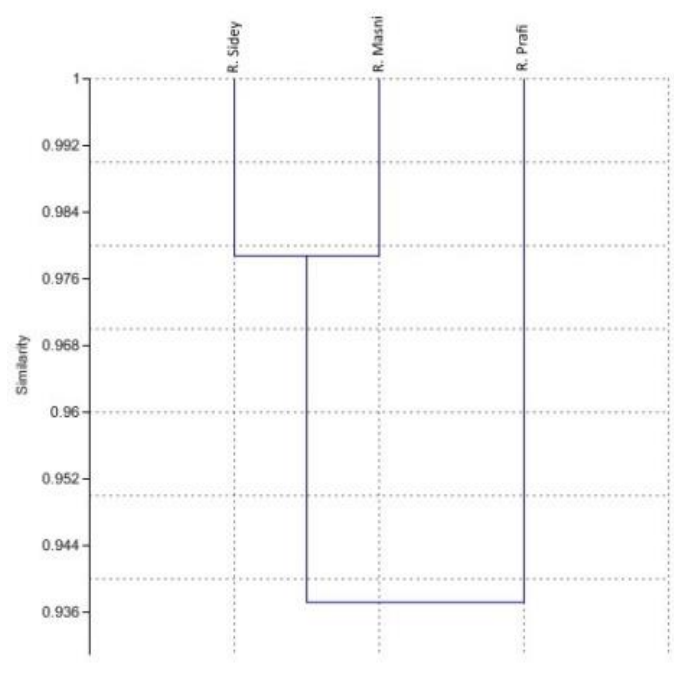

Gambar 2. Cluster PCA Ikan Mujair Jantan

Dari hasil pengukuran PCA di atas dapat diperkuat dengan pengukuran iklim mikro perairan yang menunjukkan adanya perbedaan pada ketiga rawa yang digunakan sebagai lokasi pengambilan sampel. Kondisi keasaman (pH) perairan untuk ketiga rawa bersifat netral sehingga memungkinkan ikan mujair untuk hidup dan berkembang. Kondisi pH Rawa Prafi, Masni dan Sidey berturut-turut yaitu 7,65; 6,90; dan 7,52. Nilai konduktivitas perairan untuk Rawa Sidey memiliki nilai yang tertinggi yaitu $205 \mu \mathrm{S}$, diikuti Rawa Masni dan Prafi berturut-turut yaitu $192 \mu \mathrm{S}$ dan $184 \mu \mathrm{S}$. Suhu untuk ketiga rawa memilikikisaran optimum yang mendukung 
perkembangan ikan mujair. Suhu tertinggi dimiliki oleh Rawa Sidey, yaitu $28,06^{\circ} \mathrm{C}$ diikuti Rawa Prafi dan Masni berturut-turut yaitu $27^{\circ} \mathrm{C}$ dan $26,9^{\circ} \mathrm{C}$.

Tabel 4. Iklim mikro perairan rawa yang digunakan sebagai lokasi pengambilan sampel

\begin{tabular}{lcccc}
\hline \multirow{2}{*}{ Lokasi } & \multicolumn{4}{c}{ Iklim Mikro Perairan } \\
\cline { 2 - 5 } & $\mathbf{p H}$ & Konduktivitas & Kecerahan & Suhu \\
Rawa Prafi & 7,65 & 184 & $450 \mathrm{~cm}$ & 27 \\
Rawa Masni & 6,90 & 192 & $125 \mathrm{~cm}$ & 26.9 \\
Rawa Sidey & 7,52 & 205 & $178 \mathrm{~cm}$ & 28,06 \\
\hline
\end{tabular}

Menurut para peneliti berbagai macam faktor yang dapat menjadi penyebab menurunnya tingkat keanekaragaman ikan air tawar dapat di klasifikasikan menjadi 6 kategori primer yaitu hilang/berubahnya habitat (Ismail, 2014), exploitasi berlebihan (Kurniawan et al. 2013), pencemaran (Fithra \& Siregar, 2010), persaingan dalam pengunaan air, pemanasan global (Widiarto et al. 2012) dan introduksi spesies ikan asing (Umar \& Sulaiman, 2013).

Kesamaan ukuran morfologi ikan yang terdapat pada Rawa Masni dan Sidey menandakan bahwa tingkat ketersediaan daerah pemijahan (Suryanti et al. 2017) serta makanan seperti plankton (Manangkalangi et al. 2010), insekta bentik (Asriyana \& Irawati, 2018) masih tersedia dengan jumlah yang mencukupi. Sedangkan indikator ukuran morfologi yang terjadi di rawa yang berada di wilayah Prafi menunjukan ukuran lebih kecil hal ini menandakan bahwa jumlah pakan alami sudah berkurang. Ikan Mujair (Oreochormis mossambicus) dan ikan nila (Oreochormis niloticus) merupakan ikan introduksi dan dianggap sebagai suatu ancaman terhadap ikan asli (Indegenous Species) di perairan air tawar Indonesia (Sentosa \& Wijaya, 2012) dan sejumlah negara: Brazil (Bittencourt et al. 2014) dan Australia Utara (Russell et al. 2012).

\section{SIMPULAN}

Berdasarkan hasil penelitian dapat disimpulkan bahwa variasi morfometrik menunjukkan karekter morfologi ikan mujair yang ada pada Rawa Prafi memiliki ukuran yang lebih kecil bila dibandingkan dengan ukuran ikan mujair yang ada di Rawa Masni maupun Rawa Sidey. Sehingga dapat dipastikan bahwa pertumbuhan ikan mujair yang ada di Rawa Masni dan Rawa Sidey lebih cepat hal ini menandakan kelimpahan makanan masih tetap tersedia berbeda bila dibandingkan dengan ikan mujair yang ada di Rawa Prafi tingkat kelimpahan makanan semakin berkurang dan dapat berakibat pada penurunan jumlah spesies lokal yang hidup di perairan rawa tersebut.

\section{UCAPAN TERIMA KASIH}

Terima kasih kami sampaikan kepada DRPM-DIKTI sebagai sumber pemberi dana penelitian pada Skema Penelitian Dasar.

\section{REFERENSI}

Asriyana \& Irawati, N. (2018). Makanan Dan Strategi Pola Makan Ikan Kuniran Upeneus sulphureus, Cuvier (1829) Di Perairan Teluk Kendari, Sulawesi Tenggara. Jurnal Iktiologi Indonesia, 18(1), 23-39.

Bittencourt, L.S., Pinheiro, D.A., Cárdenas, M.Q., Fernandes, B.M., \& Dias, M.T. (2014). Parasites of Native Cichlidae Populations And Invasive Oreochromis niloticus (Linnaeus, 1758) In Tributary Of Amazonas River (Brazil). Rev Bras VParasitol Vet, 23(1), 44-54. 
Crosetti, D. (2012). International Trade and Invasive Alien Species. Standards and Trade Development Facility. https://www.standardsfacility.org/sites/default/files/STDF_IAS_EN_0.pdf Retrieved June 20, 2020.

Dewiyanti, D.G.A., Irawan, B., \& Noer, M. (2015). Kepadatan dan Keanekaragaman Plankton di Perairan Mangetan Kanal Kabupaten Sidoarjo Provinsi Jawa Timur dari Daerah Hulu, Daerah Tengah dan Daerah Hilir Bulan Maret 2014. Jurnal Ilmiah Biologi, 3(1), 37-46.

Dzakaria, I., Guritno, S., \& Kartiko, S.H. (2010). Visualisasi Data Iris Mengunakan Analisis Komponen Utama Dan Analisis Komponen Utama Kernel. Jurnal Ilmu Dasar, 1(1), 31 - 38

Fithra, R.Y \& Siregar, Y.I. (2010). Keanekaragaman Ikan Sungai Kampar Inventarisasi Dari Sungai Kampar Kanan. Ilmu Lingkungan. 2 (4), 139-147.

Gunawan, E.H \& Jumadi. (2016). Keanekaragaman Jenis dan Sebaran Ikan yang Dilindungi, Dilarang dan Invasif di Kawasan Konservasi Rawa Danau Banten. Jurnal Perikanan dan Kelautan, 6(1), 67-73.

Gusriyeni, D M, Efawani, Deni, E. (2017). Inventarization And Identification of Fish In The Parit Belanda River Rumbai Pesisir District Pekanbaru, Riau. https://www.neliti.com/publications/200039/inventarization-and-

identification-of-fish-in-the-parit-belanda-river-rumbai-pes. Retrieved Juni 30, 2020.

Ismail, M. (2014). Faktor-faktor Penyebab Menurunnya Hasil Tangkapan Ikan Dan Upaya Meningkatkan Fungsi Resevat Ikan Air Tawar. Gerbang Etam, 8(2), 4-17.

Kartikasari, S.N, Marshall, A.J., \& Beehler, B.M. (2012). Ekologi Papua. Jakarta: Yayasan Pustaka Obor Indonesia dan Conservation International.

Kurniawan, M.R., Setyohad, D \& Bintoro, G. (2013). Pengaruh Pemasangan Rumpon Pada Musim Barat Terhadap Hasil Tangkapan Alat Tangkap Payang Di Perairan Tuban Jawa Timur. PSPK Student Journal, 1(1), 16-20.

Manangkalangi, E., Rahardjo, M.F., Sjafei, D.S \& Sulistiono, N. (2010). Preferensi Makanan Ikan Pelangi Arfak, Melanotaenia Arfakensis Allen, 1990 Di Sungai Nimbai Dan Sungai Aimasi, Manokwari. Jurnal Iktiologi Indonesia, 10(2), 123-135.

Naeem M., Zuberi A., Salam A., Ali M., Riaz-ulHaq M., Khalid M., Mehreen M., Nasir M F., Rasool S A \& Ishtiaq A. (2011). Some morphometric relationships of hatchery reared male population of Oreochromis mossambicus from Pakistan. African Journal of Biotechnology , 10(75), 17362-17366.

Namboothri, N., R. Ali \& A. Hiremath. (2012). Biological Invasions of Marine Ecosystems: Concerns for tropical nations. Position Paper for CBD-COP 11. Dakshin Foundation, Bengaluru and Foundation for Ecological Security, Anand.

Russell, D.J., Thuensen, P.A \& Thomson, F.E. (2012). Reproductive Strategies Of Two Invasive Tilapia Species Oreochromis mossambicus And Tilapia mariae In Northern Australia. Journal Of Fish Biology, 80(6), 76-97.

Satino. (2010). Acuan Praktikum Limnologi. Petunjuk Praktikum Limnologi (Online), http://modul limnologi. uny.ac.id, Retrieved May 132020.

Sentosa, A,A \& Wijaya, D. (2012). Struktur Komunitas Ikan Introduksi Di Danau Batur, Bali. Berita Biologi, 11(3), 329-337.

Suryanti, A., Sulistiono, Muchsin, I \& Kartamihardja, E.S. (2017). Habitat Pemijahan Danasuhan Ikan Bilih Mystacoleucus Padangensis (Bleeker, 1852) Di Sungai Naborsahan, Danau Toba, Sumaterautara. Bawal. 9 (1), 33-42. 
Syafei, L.S \& Sudinno, D. (2018). Ikan Asing Invasif, Tantangan Keberlanjutan Biodiversitas Perairan. Jurnal Penyuluhan Perikanan dan Kelautan, 12(3), 145161.

Umar, C \& Sulaiman, P.S. (2011). Status Introduksi Ikan Dan Strategi Pelaksanaan Secara Berkelanjutan Di Perairan Umum Daratan Di Indonesia. Jurnal Kebijakan Perikanan Indonesia, 5(2), 113-120.

Utomo, S.W \& Chalif, S.A. (2014). Ekosistem Perairan. Jakarta: Universitas Terbuka.

Widiarto, A.S., Purwoko, B.A., Murwono, R.P.D. (2012). Pakan Apung Artifasial Untuk Budidaya Pakan Apung Artifasial Untuk Budidaya Ikan Lele Pengaruh NAIC Dan Nutrisi Terhadap Pertumbuhan Ikan Lele Dengan Metode FCR (Feed Conversion Ratio). Jurnal Teknologi Kimia dan Industri, 2(2), 97-102. 